\title{
INDUCTION AND NATURAL KINDS ${ }^{1}$
}

\author{
HOWARD SANKEY \\ University of Melbourne
}

\section{ABSTRACT}

The paper sketches an ontological solution to an epistemological problem in the phlosophy of science Taking the work of Hilary Komblith and Brian Ellis as a point of departure, it presents a realist solution to the Humean problem of induction, which is based on a scientific essentialist interpretation of the principle of the uni formity of nature More specifically, it is argued that use of inductwe inference in science is rattonally justified because of the exis tence of real, natural kinds of things, which are characterized as such by the essential properties which all members of a kind necessarly possess in common The proposed response to inductive scepti cism combines the insights of epistemic naturalism with a metaphysical outlook that is due to scientific realism

\section{Introduction}

This paper stems from the basic realist intuition that it is the objective structure of the world which underpins the success of our epistemic practices Crudely put, it is because the world is the way it is that we are right to use induction to form beliefs about the future I seek, in short, to rehabilitate the principle of the uniformity of nature, and to employ the principle of uniformity to answer Hume's problem of induction

- Princtpia, 1(2) (1997) pp 239-54 Published by Editora da UFSC, and NEL - Epistemology and Logic Research Group, Federal University of Santa Catarına (UFSC), Brazıl 
The approach I propose is based on three distinct, but compatible philosophical positions

1 Scientific realism holds that the aim of science, towards which a great deal of progress has been made, is to discover the truth about both observable and unobservable features of an objective, mind-independent reality

11 Scientrfic essentialism is the view that the objective reality investigated by science is populated by mind-independent natural kinds of things, which are characterized as such by the fundamental, intrinsic causal powers which they possess

ili Epistemic naturalism treats epistemological questions about normative justification as broadly empinical questions about how best to pursue inquiry into the objective, natural world which we inhabit

At the most general level, my strategy is to employ an ontological theory about the constituents of reality to solve an epistemological problem about the normative justification of inductive inference In particular, I wish to appeal to the existence of natural kinds, whose members have inbult, causal powers, to explain why our use of inductive inference is epistemically justified

In outline, my argument will run as follows Induction is justified because there are, in reality, natural kinds of things These natural kinds are characterized by sets of properties which all members of a natural kind possess essentially Thus, when one makes a correct inductive inference about unobserved members of a natural kind, what makes it true that unobserved members of the kind have the properties we predict them to have is that they are members of a natural kind all of whose members possess those properties essentially 


\section{The problem of induction}

I understand the problem of induction in a straightforward way The problem is how to justify induction Two options at first suggest themselves Either induction may be justified on the basis of logic, or on the basis of experience

If 'logic' means deductive logic, there can be no logical justification of induction, since inductive inference is deductively invalid As for expenence, if it is said that induction is justified because induction has worked in the past, then induction is employed to support induction, which is circular

Here one might appeal to a principle of the uniformity of nature, which says that induction succeeds because nature is uniform The reason induction successfully predicts the future is that, since nature is uniform, the future resembles the past Because of future resemblance to the past, past regularnties will continue in the future

I think that such an appeal to the uniformity of nature is basically on the night track The trouble is, of course, that appeal to the uniformity of nature seems itself to depend on induction For, to argue that nature is uniform, one must infer from past uniformity to future uniformity, which is itself an inductive inference from past to future Given this, appeal to the uniformity of nature proceeds in a circle, since it presupposes induction

What I wish to do in this paper is to sketch a scientific essentialist response to this standard objection to the appeal to the uniformity of nature

\section{Kornblith's epıstemic naturalism}

The approach I propose is an extension of the approach taken by Hilary Kornblith in his book, Inductive Inference and its 
Natural Ground (1993) Kornblith proposes an account of the success of inductive inference, which is based on a naturalized epistemology and a realist metaphysics of natural kınds $\mathrm{He}$ distinguishes between two questions "What is the world that we may know 1t?", and "What are we that we may know the world?" (1993, p 2) In answer to the first question, he argues that

natural kinds make inductive knowledge of the world possible because the clusterning of properties charactenstic of natural kinds makes inferences from the presence of some of these properties to the presence of others reliable $(1993, p$ 7)

As for what it is about us that enables us to know the world, Kornblith argues that evolution equips the human mind with conceptual structures and inferential strategies which make it sensitive to the natural kind structure of the world Thus, there is what he describes as a "dovetal" fit between mind and world, in virtue of which inductive knowledge is possible

Kornblith appeals to the success of science to argue both that there is a fit between mind and world, and that natural kinds insure the reliability of induction I will look only at the second argument

Kornblith favours an account of natural kinds, due to Richard Boyd (1991), according to which natural kinds are homeostatic property clusters On this view, according to Kornblith,

A natural kind is a cluster of properties which, when realized together in the same substance, work to maintain and reinforce each other, even in the face of changes in the environment $(1993, \mathrm{p} 35)$

Kornblith claims that because the properties which define natural kinds "reside in homeostatic relationships, we may 
reliably infer the presence of some of these properties from the presence of others" (1993, p 36) Moreover, were it not for the fact that only certain groups of properties are capable of sustaining such homeostatic relationships, "the presence of any set of properties would be fully compatible with the presence of any other" (1993, p 36)

According to Kornblith, the best explanation of the success of induction in science is that there exist real natural kinds whose existence ensures the reliability of induction

If the scientific categones of mature sciences did not correspond, at least approximately, to real kinds in nature, but instead merely grouped objects together on the basis of salient observable properties which somehow answer to our interests, it would be utterly miraculous that inductions using these scientific categories tend to issue in accurate predictions Inductive inferences can only work, short of divine interventoon, if there is something in nature binding together the properties which we use to identify kinds Our inductive inferences in science have worked remarkably well, and, moreover, we have succeeded in identifying the ways in which the observable properties which draw kinds to our attention are bound together in nature In light of these successes, we can hardly go on to doubt the existence of the very kunds which serve to explain how such successes were even possible (1993, pp 41-2)

It is noteworthy here that, instead of arguing for the reliability of induction, Kornblith takes such reliability as something given which is in need of explanation His claim is that the best explanation of the reliability of induction is that there exist real kinds in nature, which our inductive inferences latch on to

It is evident, then, that Kornblith does not seek to justify induction in the sense of giving a non-circular basis for expecting induction to continue to be reliable in the future 
Rather, he assumes that induction is reliable in order to argue that natural kinds must exist, since therr existence is the best explanation of its reliability In other words, he argues for the existence of natural kinds on the basis of the reliability of induction, rather than arguing for the rationality of induction, given their existence

In arguing this way, Kornblith's project shows its true Quinean colours For, in simply assuming the reliability of induction, and thereby falling to confront inductive scept1cism, Kornblith's approach is informed both by what he at one point describes as a "robust antiskepticism" (pp 4-5) and by an approach to epistemological problems which derives from Qunean naturalism While I am broadly sympathetic both to anti-scepticism and epistemic naturalism, I wish to depart from Kornblith by confronting inductive scepticism directly In particular, I wish to argue against the inductive sceptic that it is the existence of real kinds in nature which justifies our use of induction

\section{Ellis's scientific essentıalısm}

On the view I propose, we may employ the principle of the uniformity of nature to justify induction But I do not understand the principle of uniformity in the usual way Customary formulations of the principle of uniformity involve claims to the effect that the future will resemble the past, or that things which have always occurred together previously will continue to do so But rather than understand the uniformity of nature as any sort of blanket resemblance of past to future, I understand it in terms of the law-governed behaviour of objects

More specifically, I take the view that the laws of nature are at base the inbuilt causal powers of things which belong to natural kinds This view, which has recently been 
proposed by Brian Ellis, is the position of scientific essentialism I will introduce the leading ideas of Ellis's essentialist theory of laws of nature, and then explain how this theory accounts for the uniformity which underlies induction

Ellis presents his theory of laws of nature in opposition to what he sees as the dominant metaphysic of contemporary Anglo-American philosophy, which he characterizes as both mechanist and Humean According to this metaphysical view, matter is essentially passive or inert The behaviour of matenal objects 1s, however, governed by laws of nature, which constitute nothing more than empirical regularities which hold universally These laws of nature are contingent regularities, which are entirely distinct from the nature or intrinsic properties of the material objects themselves Hence, the very same set of objects which exist in our world might exist completely unchanged in some other possible world that is governed by an entirely different set of natural laws

By contrast with the mechanist or Humean metaphysic, Ellis argues that the fundamental properties of matenal objects are not passive but active They have, he says, "the nature of powers, capacities and propensities" (forthcoming, [a] p 1) Such powers, capacties and propensities cannot be reduced to more basic inactive or categoncal properties of things Rather, they constitute the irreducible dispositions of things to behave in certain ways under given circumstances

The view that the behaviour of material objects is due to irreducible causal powers leads Ellis to reject the Humean account of laws as mere empinical regularities For, given that objects possess real causal powers, the laws of nature must be something more than the mere regular behaviour of inert matter Rather, the laws of nature, for Ellis, are descriptions of the behavioural patterns of things, which are made true by the possession by those things of real, inbult causal powers 
Given that the most basic properties of things are irreducible causal powers, it follows that the laws of nature are necessarily true For if material things may not lose their fundamental properties without ceasing to be what they are, the possession of those properties is crucial to their identity But since laws of nature depend on the basic causal powers of things, in any world in which the things exist the laws describing the causal powers must be true For they would not be those things if they did not possess those powers

As for natural kinds, Ellis argues that the fundamental kinds of things are characterized as such by the intrinsic causal powers of things belonging to those kinds, which constitute the Lockean real essences of such kinds (forthcoming [a], p 5) These powers are, at base, the irreducible dispositional properties of the individual members of natural kinds, and it is the behavioural manifestations of these dispositions which are described by the laws of nature which govern causal process and interactions (cf forthcoming [a], p 4, [b], p 8) Because it is the intrinsic causal powers or dispositional properties which constitute the real essences of natural kinds, possession of such powers or properties is crucial to the identity of natural kinds In particular, if a thing is to be a member of a given natural kind, then, necessarlly, it must possess the set of intrinsic powers and dispositions which are essential to that kind If it does not do so, then it cannot be a member of that kind

\section{An essentialist response to Hume}

As we saw before, Kornblith argues that the best explanation of the success of scientific induction is the existence of natural kınds, which possess homeostatic property clusters, the cooccurrence of which assures the reliability of induction This argument takes the success of induction as a given fact, and 
seeks to provide an explanation for this success As such, Kornblith fails to address Hume's sceptical challenge, which is to show that we are rationally justified in expecting induction to succeed in the future ${ }^{2}$

As ninted previously, I wish to argue that induction is justified because nature is uniform I do not understand the principle of the uniformity of nature as any sort of blanket assertion that the future resembles the past Rather, I see it as grounded in the properties of individual substances More specifically, nature is uniform in the sense that it contains natural kinds, all of whose members possess a common set of essential properties

We may think of the claim that nature is uniform as the claim that the world is governed by laws of nature This is because the essential properties of things are, in fact, the fundamental causal capacities of members of natural kinds So, when we discover that observed phenomena are governed by laws of nature, this is because we are discovering natural uniformities which are grounded in the basic causal powers of things which belong to natural kinds

My response to Hume, then, is that we are rational to employ induction when we form our beliefs about the future because nature is, in fact, uniform It is uniform in the sense that the fundamental kinds of things which exist are natural kinds of things, which possess essential sets of properties Because all members of a kind possess the same essential properties, unobserved members of a kind will possess the same properties as members of the kind which have already been observed

This is why, when we infer that an unobserved object will have a property which observed objects of the same kind have, we turn out to be right For having such a property is just part of what it is to be an object of the same kind as the other objects Thus, what makes it rational to make inductive 
predictions about objects which belong to kinds is simply that it is part of the nature of objects of a given kind to have certain properties So, as Kornblith nghtly argues, it is nature that grounds inductive inference

\section{Objections}

The account I have sketched is simplified and incomplete I wish now to address a number of objections which may be raised against it

Objection one The claim that induction is justified by the existence of natural kinds must ultimately run in a circle For the claim rests on the doctrine of scientific essentialism, which is itself based on an inference to the best explanation It must be argued, for example, that the existence of natural kinds with essential properties is the best explanation of the success of science The trouble is that inference to the best explanation is itself a form of inductive inference So, in the end, the appeal to natural kinds to justify induction must use induction to justify induction

Reply It is, in the first place, not clear that inference to the best explanation has to be construed as a form of inductive inference Some have suggested that inference to the best explanation is best construed as a kind of deductive argument based on an epistemic principle of inference ${ }^{3}$

But, let that pass We may grant that inference to the best explanation is a form of induction, at least for the sake of argument Even so, it still does not follow that the proposed justification of induction is circular For the inference to the best explanation, on which scientific essentialism is based, is a quite distinct argument from the inductive inferences which the existence of natural kinds serves to ground

This point may be best seen if we make the simplifying assumption that the sort of inductive inference at issue is low- 
level enumerative induction about the properties of observable kinds of things Such an inference has the form

All observed A's have been B's
Therefore all A's are B's

Such an enumerative inference proceeds from a premise about the features of observed A's to a conclusion about the features of unobserved B's As such, it contrasts sharply with the argument for scientific essentialism, which might be cast as follows

\section{Science is successful}

The existence of natural kinds is the best explanation of the success of science

Therefore, there are natural kinds

An argument of this kind is an argument for the existence of natural kinds which proceeds from the claim that their existence is the best explanation of the success of science Thus, at the very least, it may be sard that the present defence of induction is not carcular in the sense of using enumerative induction to justify enumerative induction Whether it is ultimately circular in any deeper sense is as yet unclear

Objection two The approach rests on a fundamental mistake For it attempts to solve an epistemological problem on the basis of ontological assumptions One cannot employ ontological assumptions to solve an epistemological problem, since epistemological problems are prior to ontological ones Until it has been shown that we have knowledge about the world, we cannot appeal to any assumptions about the way things stand in the world Hence, to appeal to ontological considerations to resolve an epistemological problem is to invert the proper order of philosophical argument ${ }^{4}$ 
Reply It is, in the first place, highly implausible to suppose that epistemology might proceed entirely in the absence of ontological assumptions At the very least, epistemological reflection on the nature of knowledge must include reflection on what knowledge is in general More specifically, it must also include reflection on the nature of knowers or epistemic agents, as well as on the kinds of things which may be the object of knowledge But, given that appeal must be made to both knowers and things that may be known, it would seem that no epistemology can proceed in the complete absence of ontological assumptions

Admittedly, the present account of the justification of inductive inference does deploy a rather rich array of ontological assumptions about such things as natural kinds and essential properties One might think that such assumptions go well beyond what is needed to address an epistemological problem However, it is by no means clear that there is any need to reduce one's ontological assumptions merely for the sake of minimizing such assumptions If the correct metaphysical picture is one which includes natural kinds and essential properties, and the existence of such kinds and properties has implications for inductive inference, then there seems no reason not to include such assumptions in one's epistemological model

Objection three Induction cannot be grounded in natural kinds, for there are sound inductive inferences about artefacts and other non-natural kinds One may infer inductively about cars, for example Thus, in the past, moving into the path of a rapidly moving car has been dangerous, hence in future moving into the path of a rapidly moving car will also be dangerous

Reply It is true that good inductive inferences are not restricted to natural kinds One may make good inductive inferences about artefacts such as cars What is not clear is 
whether the artefactual nature of the items concerned is relevant to the success of inductions about such things What is dangerous about moving into the path of a moving car is not just that one may be struck by the car, but that one might get struck by an object with a large mass moving at a high velocity The risks involved are not dissilimar to those involved in being run down by a charging buffalo, or struck by a boulder rolling down a hillside or a falling meteonte Thus, it may very well be the case that one is only able to make reliable inductive inferences about artefacts and other non-natural kinds, to the extent that such inferences turn on facts about them which obtain in virtue of their being members of natural kinds

Objection four The account only applies to the essential properties of natural kinds Yet not all inductive inferences concern the essential properties of kinds For one can well imagine that there may be inductive inferences which range over the accidental properties of kinds of things Hence, the account mistakenly assumes that inductive inference is restricted to the essential properties of things

Reply I conjecture that a crucial distinction between good and bad induction hinges on the distinction between essential and accidental properties For the most part, good inductive inferences project essential properties, whereas bad ones project accidental properties One might perhaps distinguish three cases of possible relevance here (1) inductive inferences which range over essential properties, (11) inductive inferences which range over accidental properties, (ii) inductive inferences which range over accidental properties that are determined by essential properties Inductions of type (1) tend to succeed, those of type (11) tend to fall, and those of type (111) may succeed if the relevant link between essential and accidental properties obtains 
Objection five The account is, perhaps, plausible for induction in the physical sciences, where the fundamental particles constitute natural kinds But there are no natural kinds in biology Yet surely there is sound inductive inference in the life sciences ${ }^{5}$

Reply It is true that any account of scientific induction must apply to induction in the life sciences, as well as in the physical sciences It is not clear, though, that the present account need address this issue For what the present objection really does is rase the issue of reductionism If biological kinds can be reduced to physical kinds, then inductive inferences which range over biological kinds will hold because biological kinds reduce to physical kinds But if biological kinds fail to reduce to physical kinds, then inductions about biological kinds will hold in virtue of the essential properties of such kinds In either case, there will be sound inductive inference about biological kinds

\section{Concluding thought}

I do not suppose that in this short paper I have solved the problem of induction But what I do hope to have done is to sketch out some ideas, which will provide the basic outlines of a solution to the problem In particular, I hope to have sketched here a solution to the problem of a kind which will be attractive to a philosopher who is attracted by the doctrines of scientific realism, scientific essentialism and epistemic naturalism

\section{References}

Armstrong, David 1983 What is a Law of Nature? Cambridge Cambridge Unıversity Press 
Armstrong, David 1995 'What Makes Induction Rational?' In J Misiek (ed), The Problem of Rationality in Science and its Philosophy Dordrecht Kluwer Academic Publishers, 45-54

Boyd, Ruchard 1991 'Realism, Ant1-Foundationalism and the

Enthusiasm for Natural Kinds' Philosophical Studies, 61 $127-48$

Couvalis, George 1997 The Philosophy of Science Science and Objectivity London Sage

Ellıs, Brian 1992 'Scientific Essentialism' Vuctorian Centre for the History and Philosophy of Science, preprint 1/92

- 1996 'Natural Kinds and Natural Kind Reasoning' In

P J Riggs (ed), Natural Kinds, Laws of Nature and Scientific Methodology Dordrecht Kluwer Academic Publishers, 1128

(forthcoming [a]) 'Causal Powers and Laws of Nature' In $\mathrm{H}$ Sankey (ed ), forthcoming Causation and Laws of Nature Dordrecht Kluwer Academic Publishers

Ellis, Brian (forthcoming [b]) 'Reply to Bigelow' In H Sankey (ed), forthcoming Causation and Laws of Nature Dordrecht Kluwer Academic Publishers

Ellis, Brian \& Lierse, Caroline 1994 'The Fundamental Importance of Natural Kinds' Victorian Centre for the History and Philosophy of Science, preprint 3/94

Hetherington, Stephen Cade 1997 Review of Kornblith Inductive Inference and its Natural Ground, Australasian Journal of Philosophy, 75 122-4

Kornblith, Hilary 1993 Inductive Inference and Its Natural Ground Cambridge, Mass MIT Press

Musgrave, Alan 1988 'The Ultımate Argument for Scientıfic Realism' In R Nola (ed) Relativism and Realism in Science Dordrecht Kluwer Academic Publishers, 229-52

\section{Keywords}

Hilary Kornblith, Brian Ellıs, essentıalısm, natural kınds, induction 


\section{Howard Sankey Department of History and Philosophy of Sclence University of Melbourne Parkwille, Victoria Australia, 3052} h sankey@hps unımelb edu au

\section{Nutes}

1 This paper was presented at Departamento de Filosofia, Universidade de Brasilia, 3 October 1997 I am grateful to Paulo Abrantes for the invitation to speak at Brasilia, and to the members of the audience for their comments and the lively discussion of points rassed in the paper

${ }^{2}$ Opinion divides as to whether Kornblith does address Hume's problem directly Hetherington clams that Kornblith falls to "engage with traditional - Humean - sceptical worries" (1997, p 123), whereas Couvalis argues that Kornblith "may have solved Hume's puzzle" (1997, p 49)

3 Musgrave, for example, argues that inference to the best explanation may be construed as a deductive enthymeme which tactly rests on the epistemological principle that it is reasonable to tentatively accept the best explanation of some fact $(1988, \mathrm{p} 238)$ Another option, suggested by Armstrong (1995, p 48ff), is to construe inductive inference itself as a form of inference to the best explanation (cf Armstrong, 1983, pp 52-3)

${ }^{4}$ It might, for example, be argued that one cannot justrfiably make any assumptions about the nature of reality until it has been shown that one knows both that there is an external world, and that one can have knowledge about the nature of such a world

${ }^{5}$ Alternatively, one might argue that there is a profound difference between kinds in the life sciences and kinds in physics The present account applies to kinds in the physical sciences Yet any account of induction must also apply to kinds in the life sciences 